Revista Brasil. Bot., V.31, n.4, p.659-665, out.-dez. 2008

\title{
Espécies de Vermiculariopsiella (Hyphomycetes) associadas a substratos vegetais em fragmento de Mata Atlântica, Serra da Jibóia, Estado da Bahia, Brasil ${ }^{1}$
}

\author{
MARCOS FABIO OLIVEIRA MARQUES ${ }^{2,5}$, LUIS FERNANDO PASCHOLATI GUSMÃO ${ }^{3}$ \\ e LEONOR COSTA MAIA ${ }^{4}$
}

(recebido: 03 de maio de 2007; aceito: 18 de setembro de 2008)

\begin{abstract}
Species of Vermiculariopsiella (Hyphomycetes) associated with plant debris in a fragment of Atlantic Rain Forest, "Serra da Jibóia", Bahia State, Brazil). During a survey of microfungi associated to plant debris in a fragment of Atlantic Rain Forest, Serra da Jibóia, Santa Terezinha, Bahia State, from October/2005 to June/2006, four Vermiculariopsiella species were found in association to the decomposition of leaves, petioles and twigs in this ecosystem. V. immersa (Desm.) Bender and V. cubensis (R.F. Castañeda) Nawawi, Kuthub. \& B. Sutton are new records for "Serra da Jibóia" and State of Bahia, respectively, V. cornuta (V. Rao \& Hoog) Nawawi, Kuthub. \& B. Sutton and V. falcata Nawawi, Kuthub. \& B. Sutton represent new records for South America. Descriptions and illustrations of morphologic characteristics of the four species, information about substrates and geographical distribution as well as a taxonomic key for all known species of Vermiculariopsiella are provided.
\end{abstract}

Key words - Anamorph, fungal diversity, taxonomy

RESUMO - (Espécies de Vermiculariopsiella (Hyphomycetes) associadas a substratos vegetais em fragmento de Mata Atlântica, Serra da Jibóia, Estado da Bahia, Brasil). Durante o levantamento de microfungos associados a substratos vegetais na Serra da Jibóia, Santa Terezinha, Bahia, Brasil, no período de outubro/2005 a junho/2006, foram encontradas quatro espécies de Vermiculariopsiella associadas à decomposição de folhas, pecíolos e galhos nesse ecossistema. Vermiculariopsiella. immersa (Desm.) Bender e V. cubensis (R.F. Castañeda) Nawawi, Kuthub. \& B. Sutton são novos registros para a Serra da Jibóia e Estado da Bahia respectivamente e V. cornuta (V. Rao \& Hoog) Nawawi, Kuthub. \& B. Sutton e V. falcata Nawawi, Kuthub. \& B. Sutton constituem novos registros para a América do Sul. São apresentadas descrições e ilustrações das características morfológicas das quatro espécies, informações sobre substratos e a distribuição geográfica, bem como chave para identificação de todas as espécies conhecidas de Vermiculariopsiella.

Palavras-chave - Anamórfico, diversidade fúngica, taxonomia

\section{Introdução}

A Mata Atlântica abriga uma grande diversidade de vegetais, sendo estimado que existam 13.000 espécies de angiospermas, 73\% delas endêmicas (Whitmore 1997, Brasil 2002). Por outro lado, não há estimativas sobre os fungos, que exercem papel fundamental na manutenção desse bioma. Entre os microfungos associados a substratos vegetais destacam-se os que produzem conidioma em

1. Parte da dissertação de mestrado do primeiro autor, Programa de Pós-Graduação em Biologia de Fungos da Universidade Federal de Pernambuco, Recife, PE, Brasil.

2. Universidade do Estado da Bahia, Departamento de Educação, Campus VII, Laboratório de Microbiologia (LAM), BR 407, km 127, Rod. Lomanto Júnior, 48970-000 Senhor do Bonfim, BA, Brasil.

3. Universidade Estadual de Feira de Santana, Departamento de Ciências Biológicas, Laboratório de Micologia, Caixa Postal 252, 44031-460 Feira de Santana, BA, Brasil.

4. Universidade Federal de Pernambuco, Departamento de Micologia, Av. Prof. Nelson Chaves s/n, Cidade Universitária, 50670-420 Recife, PE, Brasil.

5._Autor para correspondência: mfomarques@gmail.com esporodóquios, caracterizados por uma massa de conídios sobre um aglomerado de conidióforos curtos (estroma pulvinado), formando um pseudoparênquima (Kirk et al. 2001). Cerca de 160 gêneros de fungos conidiais produzem esporodóquio (Herrera \& Ulloa 1998).

O gênero Vermiculariopsiella foi estabelecido por Bender em 1932, com a espécie-tipo V. immersa (Desm.) Bender, caracterizado por apresentar conidioma em esporodóquio, setas numerosas, células conidiogênicas fialídicas, conídios cilíndricos, asseptados, levemente curvados, agrupados em mucilagem (Nawawi et al. 1990).

Oramasia Urries foi criada em 1956 com a espécietipo O. hirsuta e redescrita por Sutton \& Pirozynski (1963) como possuindo conidiogênese holoblástica e simpodial. Contudo, Sutton (1978) verificou que a conidiogênese é fialídica. Nag Raj (1983) sinonimizou Oramasia com Vermiculariopsiella, considerando duas variedades: $V$. immersa (Desm.) Bender var. immersa e V. immersa var. ramosa (B. Sutton) Nag Raj.

Chaetopsina ludoviciana J. L. Crane \& Schokn. foi transferida para Menisporopsis ludoviciana (J. L. Crane 
\& Schokn.) P. M. Kirk \& B. Sutton por não compartilhar características com esse gênero (Kirk \& Sutton 1985) e depois sinonimizada com V. ludoviciana (J. L. Crane \& Schokn.) R. F. Castañeda, Cano \& Guarro, pois segundo Castañeda-Ruiz et al. (1997), com base na descrição original e ilustrações, esta não constitui uma espécie de Menisporopsis. Em revisão do gênero, Nawawi et al. (1990) propuseram combinações válidas: V. cornuta (V. Rao \& de Hoog) Nawawi, Kuthub. \& B. Sutton (= Gyrothrix cornuta V. Rao \& de Hoog), V. cubensis (R. F. Castañeda) Nawawi, Kuthub. \& B. Sutton (= Oramasia hirsuta Urries var. cubensis R. F. Castañeda) e elevaram a variedade $V$. immersa (Desm.) Bender var. ramosa (B. Sutton) Nag Haj ao nível de espécie, V. ramosa (B. Sutton) Nawawi, Kuthub. \& B. Sutton, com base na diferença das setas e esporodóquio. Castañeda-Ruiz \& Kendrick (1991) propuseram a combinação de Gyrothrix microsperma (Höhn.) Piroz. para V. microsperma (Höhn.) R. F. Castañeda \& W. B. Kendr., devido à formação de conídios com base arredondada e ápice agudo e fialídes com ápice conidiogênico aberto; no entanto, esta combinação não foi aceita devido à ausência de conidioma em G. microsperma.

Hoje, Vermiculariopsiella, gênero com ampla distribuição (Kirk et al. 2001), é constituído por doze espécies: V. arcicula Pasqual. \& Zucconi; V. cornuta (V. Rao \& de Hoog) Nawawi, Kuthub. \& B. Sutton; $V$. cubensis; V. elegans Keshavaprasad, D’Souza \& Bhat; $V$. endophytica Puja, Bhat \& K.D. Hyde; V. falcata Nawawi, Kuthub. \& B. Sutton; V. immersa; V. indica Keshavaprasad, D'Souza \& Bhat; V. parva Keshavaprasad, D'Souza \& Bhat; V. parvula Nawawi, Kuthub. \& B. Sutton; V. ramosa; V. spiralis Crous, Wingf. \& W. B. Kendr. e uma variedade, V. immersa var. immersa (Kirk \& Cooper 2007). Estas espécies diferem quanto à morfologia e dimensões dos esporodóquios, setas, células conidiogênicas e conídios. Algumas espécies são endofíticas, outras ocorrem sobre folhas em decomposição e substratos vegetais submersos (Castañeda-Ruiz 1986, Rao \& de Hoog 1986, Nawawi et al. 1990, Grandi \& Gusmão 2002, Keshavaprasad et al. 2003, Puja et al. 2006).

O objetivo deste trabalho foi registrar a diversidade de espécies de Vermiculariopsiella que ocorrem na Mata Atlântica e ampliar os conhecimentos sobre a distribuição do gênero.

\section{Material e métodos}

O material descrito nesse estudo foi originado de coletas de serapilheira, realizadas entre outubro/2005 a junho/2006 em um fragmento de Mata Atlântica, Serra da Jibóia, município de Santa Terezinha (1251' S e 39²8' W), uma das 147 áreas prioritárias para conservação desse bioma (Brasil 2002).

As amostras de material vegetal foram recolhidas em saco de papel Kraft e transportadas ao laboratório, onde foram submetidas à lavagem em água corrente, secagem sobre papel toalha em temperatura ambiente e posteriormente colocadas em câmaras-úmidas (placa de Petri com papel filtro e água destilada esterilizada), que foram acondicionadas em uma caixa de isopor $(170 \mathrm{~L})$. Periodicamente a caixa era aberta por alguns minutos para circulação do ar e, após 72 horas, o material incubado foi observado em estereomicroscópio (Castañeda-Ruiz et al. 2006, modificado).

Estruturas reprodutivas dos microfungos foram transferidas, com auxílio de agulhas finas, para meio de montagem semipermanente contendo resina PVL (álcool polivinílico com lactofenol) (Trappe \& Schenck 1982). A identificação foi efetuada utilizando bibliografia especializada e o material depositado no Herbário da Universidade Estadual de Feira de Santana (HUEFS) e/ou no Herbário do Departamento de Micologia da Universidade Federal de Pernambuco (URM).

\section{Resultados e discussão}

Vermiculariopsiella cornuta (V. Rao \& de Hoog) Nawawi, Kuthub. \& B. Sutton, Mycotaxon 37: 181. 1990. $\equiv$ Gyrothrix cornuta V. Rao \& de Hoog, Stud. Mycol. 28: 68. 1986.

Figuras. 1-5

Conidioma em esporodóquio, solitário; setas ramificadas dicotomicamente, paredes espessas, eretas, retas, septadas, lisas, castanho-escuras a negras, estipes 78-139,5 × 7,5$15 \mu \mathrm{m}$; ápice com 1-4 ramificações dicotômicas, última ramificação pontiaguda, afinando-se e encurvando-se na maturidade, castanho-escuras, última ramificação castanha 43,5-72 × 4,5-7,5 $\mu \mathrm{m}$; conidióforos curtos, densamente agrupados, hialinos; células conidiogênicas polifialídicas, cilíndricas a obclavadas, lisas, hialinas; conídios solitários, asseptados, cilíndricos, ápice agudo e levemente curvo e base obtusa, lisos, agrupados em mucilagem, hialinos, 12,6-16,2 × 1,0-1,2 $\mu \mathrm{m}$.

As características morfológicas e as dimensões das estruturas estão de acordo com a descrição original da espécie (Rao \& de Hoog 1986), exceto pelas menores dimensões do conídio no material examinado e as ramificações, afinando-se e curvando-se na maturidade, detalhe não observado na descrição original. Essa espécie foi originalmente descrita na Índia como Gyrothrix cornuta Rao \& de Hoog sobre folhas mortas (Rao \& de Hoog 1986). No entanto, o gênero Gyrothrix (Corda) Corda é caracterizado por possuir células conidiogênicas 
poliblásticas, evidentes, solitárias e percurrentes, anelídicas, conídios arranjados no ápice da célula conidiogênica e freqüentemente se destacando em grupos (Pirozynski 1962, Ellis 1971, 1976). Assim, posteriormente $G$. cornuta foi transferida para o gênero Vermiculariopsiella por Nawawi et al. (1990), por apresentar conidioma setoso, fiálides com colaretes e conídios hialinos, com uma curta papila protuberante na base, marcando o ponto de destacamento, agrupados em mucilagem. Este registro constitui a primeira citação da espécie para o neotrópico.

Material examinado: BRASIL. BAHIA: Santa Terezinha, Serra da Jibóia, sobre folhas em decomposição, 10-XII-2005, M.F.O. Marques s.n. (HUEFS105738); galhos em decomposição, 27-X-2005, M.F.O. Marques s.n. (URM78842) e pecíolos em decomposição, 17-II-2006, M.F.O. Marques s.n. (URM78841).
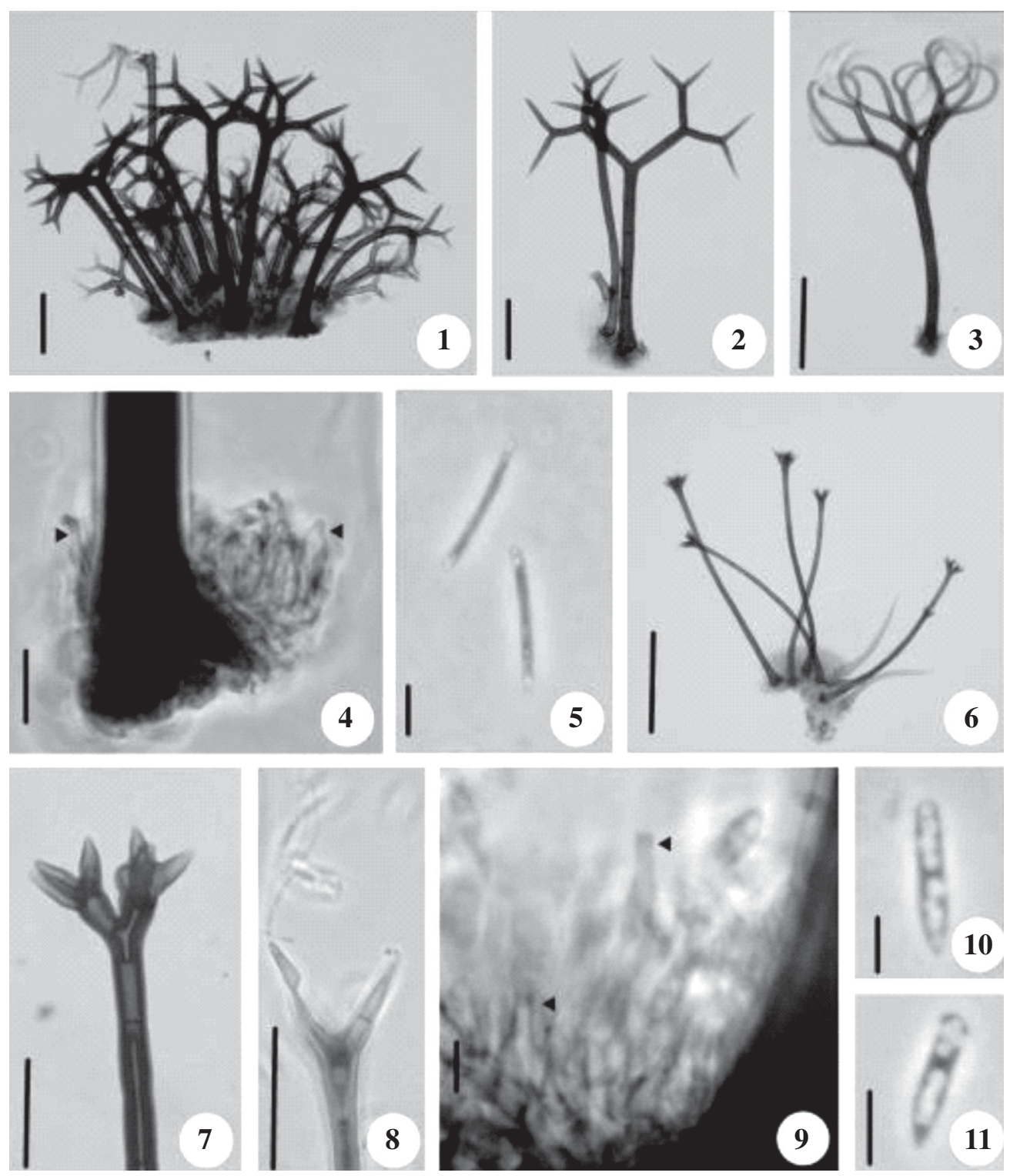

Figuras 1-5. Vermiculariopsiella cornuta. 1. Esporodóquio. 2. Seta com três ramificações dicotômicas. 3. Seta com ramificações curvas na maturidade. 4. Células conidiogênicas. 5. Conídios. 6-11. V. cubensis. 6. Esporodóquio. 7. Ápice da seta. 8. Apêndice filiforme. 9. Células conidiogênicas. 10-11. Conídios. Barra $=50 \mu \mathrm{m}(1-3) ; 10 \mu \mathrm{m}(4,8,9) ; 5 \mu \mathrm{m}(5,10,11) ; 100$ $\mu \mathrm{m}(6) ; 25 \mu \mathrm{m}(7)$.

Figures 1-5. Vermiculariopsiella cornuta. 1. Sporodochia. 2. Setae with three dichotomical branches. 3. Setae with branches curved in maturity. 4. Conidiogenous cells. 5. Conidia. 6-11. V. cubensis. 6. Sporodochia. 7. Apex of setae. 8. Filiform appendage. 9. Conidiogenous cells. 10-11. Conidia. Bar $=50 \mu \mathrm{m}(1-3) ; 10 \mu \mathrm{m}(4,8,9) ; 5 \mu \mathrm{m}(5,10,11) ; 100 \mu \mathrm{m}(6) ; 25 \mu \mathrm{m}(7)$. 
Distribuição geográfica e substratos: Índia; folhas em decomposição não identificadas (Rao \& de Hoog 1986).

Vermiculariopsiella cubensis (R. F. Castañeda) Nawawi, Kuthub. \& B. Sutton, Mycotaxon 37: 180. 1990. $\equiv$ Oramasia hirsuta var. cubensis R. F. Castañeda, Fungi Cubenses (La Habana): 11. 1986.

Figuras 6-11

Conidioma em esporodóquio, solitário; setas numerosas, com paredes espessas, eretas, retas ou flexuosas, septadas, lisas, extremidades com ramificações dicotômicas, castanho-escuras, 192-425 × 10-20 $\mu$ m; ápice com 2-4 ramificações primárias e 4-8 secundárias; ramificações dicotômicas com células cônicas, septadas ou não, lisas, às vezes com apêndice filiforme, castanho-claras, 13,5$33 \times 4,5-6 \mu \mathrm{m}$; conidióforos curtos, densamente agrupados, hialinos; células conidiogênicas monofialídicas, hialinas; conídios solitários, asseptados, cilíndricos, base arredondada e ápice levemente agudo e curvo, lisos, gutulados, agrupados em mucilagem, hialinos, 9,6-15 × 1,2-1,8 $\mu \mathrm{m}$.

O material examinado apresenta as características típicas para a espécie (Castañeda-Ruiz 1986, MercadoSierra et al. 1997, Grandi \& Gusmão 2002). Contudo, os conídios apresentaram menores dimensões do que os referidos por Mercado-Sierra et al. (1997), alterando a amplitude das dimensões dos conídios da espécie. Grandi \& Gusmão (2002) a referiram pela primeira vez para o Brasil no Estado de São Paulo. Esta espécie difere das demais descritas para o gênero, pelo número de ramificações dicotômicas ou tricotômicas das setas, apêndices filiformes e conídios gutulados.

Material examinado: BRASIL. BAHIA: Santa Terezinha, Serra da Jibóia, sobre pecíolos em decomposição, 15-X-2005, M.F.O. Marques s.n. (HUEFS10539).

Distribuição geográfica e substratos: Brasil: São Paulo, em folhas em decomposição de Tibouchina pulchra Cogn. (Grandi \& Gusmão 2002); Cuba: folhas em decomposição de Syzygium jambos (L.) Alston (Castañeda-Ruiz 1986).

Vermiculariopsiella falcata Nawawi, Kuthub. \& B. Sutton, Mycotaxon 37: 175. 1990.

Figuras 12-15

Conidioma em esporodóquio, solitário; setas numerosas, com paredes espessas, eretas, retas ou flexuosas, septadas, lisas, castanho-escuras, 126-354 × 4,5-9 $\mu \mathrm{m}$; conidióforos curtos, densamente agrupados, hialinos; células conidiogênicas monofialídicas, cilíndricas, com distintos colaretes, lisas, castanhas; conídios solitários, 3-septados, falcados, ápice agudo e levemente curvo e base às vezes truncada ou arredondada, lisos, gutulados, agrupados em mucilagem, hialinos, 30-39,6×1,2-1,3 $\mu$ m.

As dimensões das estruturas estão de acordo com o referido por Nawawi et al. (1990), mas os conídios apresentam-se um pouco menores em comparação ao originalmente descrito $(36-47 \times 1,5-2 \mu \mathrm{m})$. Os conídios falcados, 3-septados, gutulados, são únicos para essa espécie. Vermiculariopsiella falcata apresenta seta não ramificada como $V$. arcicula, $V$. immersa, $V$. parvula e V. spiralis, diferindo destas principalmente pelos conídios falcados, 3-septados (Pasqualetti \& Zucconi 1992). A espécie está sendo referida pela terceira vez para o mundo, sendo esta a primeira citação para a América do Sul.

Material examinado: BRASIL. BAHIA: Santa Terezinha, Serra da Jibóia, sobre folhas em decomposição, 02-I-2006, M.F.O. Marques s.n. (HUEFS105741).

Distribuição geográfica e substratos: Cuba: folhas em decomposição não identificadas (Castañeda-Ruiz, dados não publicados); Malásia: galhos submersos em decomposição, não identificados (Nawawi et al. 1990).

Vermiculariopsiella immersa (Desm.) Bender, Mycologia 24: 412. 1932. E Excipula immersa Desm., Bull. Soc. Bot. Fr. 4: 911, 1857. इDinemasporium immersum (Desm.) Sacc., Syll. fung. (Abellini) 10:439. 1892. =Vermiculariopsis immersa (Desm.) Höhn., Ber. dt. bot. Ges. 36: 317. 1918. = Dinemasporium adenatum Petrak, Bot. Jahrb. Syst. Beiblatt 62: 150. 1929.

= Oramasia hirsuta Urries, An. Inst. Bot. A. J. Cavanilles 14: 168, 1956.

Figuras 16-19

Conidioma em esporodóquio, solitários; setas numerosas, com paredes espessas, eretas, retas ou flexuosas, septadas, lisas, castanhas, 354-690 ×6-13,5 $\mu \mathrm{m}$; conidióforos curtos, densamente agrupados, hialinos; células conidiogênicas monofialídicas, subcilíndricas a lageniformes, lisas, com colaretes recurvados, hialinas; conídios solitários, asseptados, cilíndricos, ápice agudo e base obtusa, lisos, agrupados em mucilagem, hialinos, 13,5-20,4 × 1,6-1,9 $\mu \mathrm{m}$.

Os caracteres do material estudado estão de acordo com o mencionado por Nag Raj (1983) e Nawawi et al. (1990), exceto pela dimensão das setas e a largura dos conídios, menores do que o referido por Nawawi et al. (1990). Vermiculariopsiella immersa assemelha-se a $V$. arcicula Pasqualetti \& Zucconi e V. spiralis pelas células conidiogênicas com ápice recurvado, diferindo pelo conídio fusiforme a curvado e a seta espiralada, respectivamente (Crous et al. 1995). No Brasil, V. 

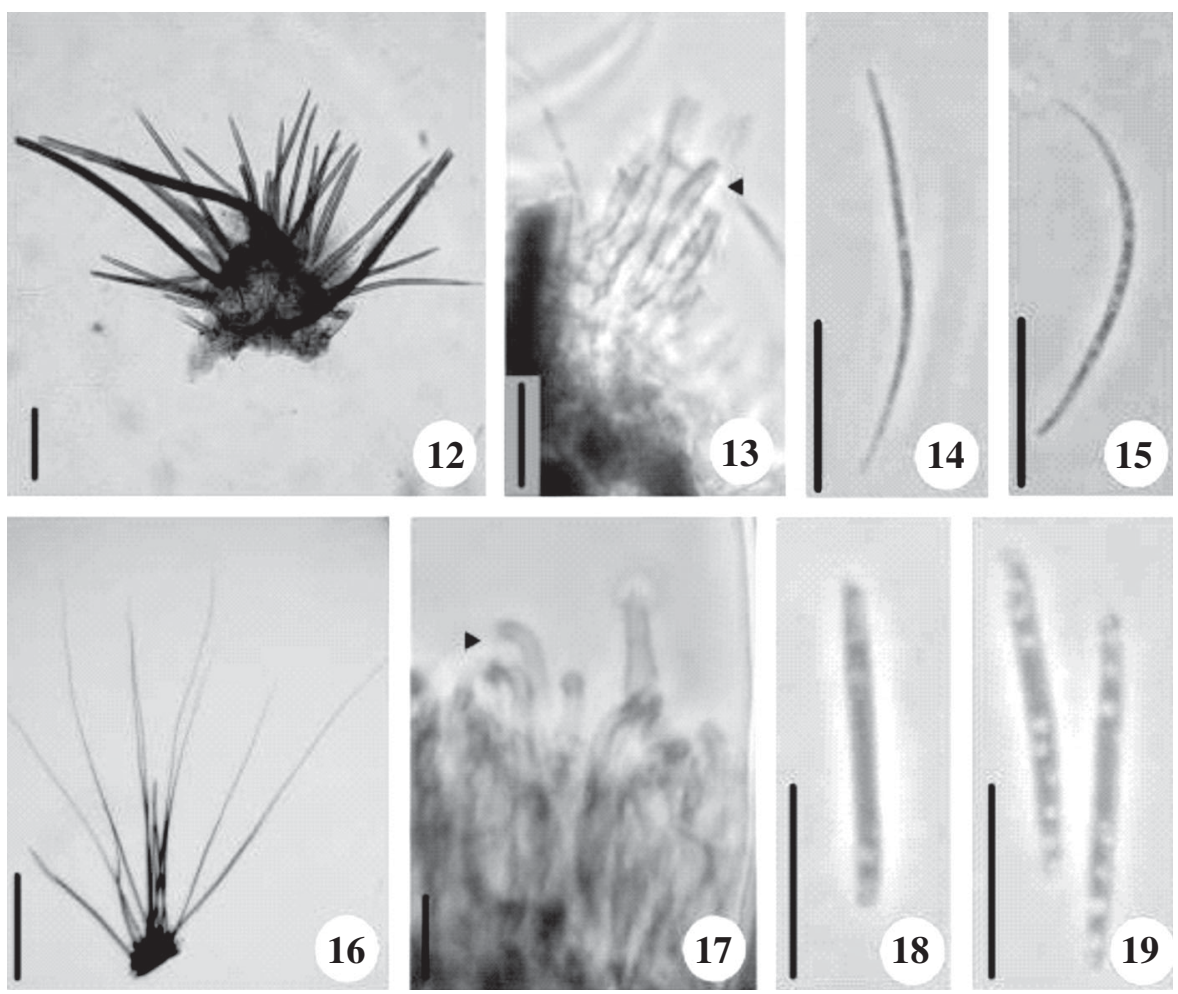

Figuras 12-15. Vermiculariopsiella falcata. 12. Esporodóquio. 13. Células conidiogênicas. 14-15. Conídios. 16-19. V. immersa. 16. Esporodóquio. 17. Células conidiogênicas. 18-19. Conídios. Barra $=50 \mu \mathrm{m}(12) ; 10 \mu \mathrm{m}$ (13, 17-19); $35 \mu \mathrm{m}$ (14-15); $200 \mu \mathrm{m}(16)$.

Figures 12-15. Vermiculariopsiella falcata. 12. Sporodochia. 13. Conidiogenous cells. 14-15. Conidia. 16-19. V. immersa. 16. Sporodochia. 17. Conidiogenous cells. 18-19. Conidia. Bar $=50 \mu \mathrm{m}(12) ; 10 \mu \mathrm{m}(13,17-19) ; 35 \mu \mathrm{m}(14-15) ; 200 \mu \mathrm{m}(16)$.

immersa foi coletada por Sutton (1978) ainda com a denominação anterior de Oramasia hirsuta var. hirsuta, nos Estados do Espírito Santo, Minas Gerais e Pernambuco. Para a Bahia foi registrada associada a folhas em decomposição na Chapada Diamantina (Gusmão et al. 2005). Vermiculariopsiella immersa aparenta ser a espécie mais comum, ocorrendo em folhas, pecíolos e cascas em decomposição de uma variedade de vegetais em habitats temperados e tropicais (Sutton 1978, 1993, Nawawi et al. 1990, Nag Raj 1983).

Material examinado: BRASIL. BAHIA: Santa Terezinha, Serra da Jibóia, sobre folhas em decomposição, 12-XII-2005, M.F.O. Marques s.n. (HUEFS105740) e pecíolos em decomposição, 16-II-2006, M.F.O. Marques s.n. (URM78843).
Distribuição geográfica e substratos: Austrália, Grécia, Itália, Espanha, Estados Unidos, Reino Unido: substratos não descritos (Sutton 1993); Brasil: sobre folhas em decomposição de Esenbeckia macrocarpa Hub., Eucalyptus grandis W. Hill \& Maiden e Eucalyptus sp. (Sutton 1978), Caesalpinia echinata Lam. (Grandi \& Silva 2006), folhas não identificadas (Gusmão et al. 2005); Brunei: folhas e galhos submersos, não identificados, Malásia: folhas em decomposição submersas, não identificadas (Nawawi et al. 1990); Cuba: sobre folhas não identificadas (Castañeda-Ruiz, dados não publicados); França: folhas de Quercus sp. e Prunus lusitanica L. (Sutton 1993); Índia: folhas de Quercus ilex L., $Q$. coccifera L. e Loranthus sp. (Nag Raj 1983); Malawi: sobre folhas não identificadas (Sutton 1993).

Chave dicotômica para as espécies de Vermiculariopsiella da Serra da Jibóia

1. Setas não ramificadas

2. Setas espiraladas com ápice afilado ou arredondado V. spiralis

2. Setas eretas, retas ou flexuosas 
3. Células conidiogênicas com ápice reto

4. Células conidiogênicas com distintos colaretes

5. Conídios falcados, 3-septados, ápice curvo e pontudo

V. falcata

5. Conídios cilíndricos, asseptados, com ápice levemente curvo e pontiagudo

V. parvula

4. Células conidiogênicas subcilíndricas, com colaretes inconspícuos

6. Conídios cilíndricos 37-42 × 10-13 $\mu \mathrm{m}$

V. endophytica

6. Conídios cilíndricos $<35 \mu \mathrm{m}$ comprimento

7. Conídios 12-15 $\mu \mathrm{m}$ comprimento

V. parva

7. Conídios com dimensões maiores

8. Conídios 20-25 × 6-8 $\mu \mathrm{m}$ V. elegans

8. Conídios 22-30 × 8-11 $\mu \mathrm{m}$

V. indica

3. Células conidiogênicas com ápice recurvado

9. Conídio fusiforme, geralmente curvo, 15-19,5 × 2,5-38 $\mu \mathrm{m}$

V. arcicula

9. Conídio cilíndrico, 13,5-20,4 × 1,6-1,9 $\mu \mathrm{m}$

V. immersa

1. Setas ramificadas

10. Setas com ramificações primárias e secundárias curtas; células terminais com um apêndice

filiforme

$V$. cubensis

10. Setas com ramificações dicotômicas

11. Seta com uma ramificação dicotômica

V. ramosa

11. Seta com três ramificações dicotômicas

V. cornuta

\section{Referências bibliográficas}

BRASIL. 2002. Avaliação e ações prioritárias para a conservação da biodiversidade da Mata Atlântica e Campos Sulinos. In Biodiversidade brasileira: Avaliação e identificação de áreas e ações prioritárias para conservação, utilização sustentável e repartição dos benefícios da biodiversidade nos biomas brasileiros. Ministério do Meio Ambiente. Brasília, p.215-266.

CASTAÑEDA-RUIZ, R.F. 1986. Fungi Cubense. Cuba, Instituto de Investigaciones Fundamentales em Agricultura Tropical.

CASTAÑEDA-RUIZ, R.F. \& KENDRICK, B. 1991. Ninetynine conidial Fungi from Cuba and three from Canada. University of Waterloo Biology Series 35:1-132.

CASTAÑEDA-RUIZ, R.F., CANO, J. \& GUARRO, J. 1997. Notes on conidial fungi VI. Menisporopsis. Mycotaxon 64:335-342.

CASTAÑEDA-RUIZ, R.F., GUSMÃO, L.F.P., HEREDIAABARCA, G. \& SAIKAWA, M. 2006. Some Hyphomycetes from Brazil. Two new species of Brachydesmiella. Two new combinations for Repetophragma, and new records. Mycotaxon 95:261270.

CROUS, P.W., WINGFIELD, M.J. \& KENDRICK, W.B. 1995. Foliicolous dematiaceous hyphomycetes from Syzygium cordatum. Canadian Journal of Botany 73:224-234.

ELLIS, M.B. 1971. Dematiaceous Hyphomycetes. Commonwealth Mycological Institute, Kew.

ELLIS, M.B. 1976. More dematiaceous Hyphomycetes. Commonwealth Mycological Institute, Kew.
GRANDI, R.A.P. \& GUSMÃO, L.F.P. 2002. Hyphomycetes decompositores do folhedo de Tibouchina pulchra Cogn. Revista Brasileira de Botânica 25:79-87.

GRANDI, R.A.P. \& SILVA, T.V. 2006. Fungos anamorfos decompositores do folhedo de Caesalpinia echinata Lam. Revista Brasileira de Botânica 29:275-287.

GUSMÃO, L.F.P., GÓES-NETO, A. \& CRUZ, A.C.R. 2005. Fungos. In Biodiversidade e conservação da Chapada Diamantina (F.A Juncá, L. Funch \& W. Rocha orgs.). Ministério do Meio Ambiente, Brasília, p.225-240.

HERRERA, T. \& ULLOA, M. 1998. El reino de los hongos: mycologia básica y aplicada. Universidad Nacional Autonoma del México, México.

KIRK, P.M. \& COOPER, J. 2007. Index fungorum. http:// www.indexfungorum.org (acesso em 13/01/2007).

KIRK, P.M. \& SUTTON, B.C. 1985. A reassessment of the anamorph genus Chaetopsina (Hyphomycetes). Transactions of the British Mycological Society 85: 709-717.

KIRK, P.M., CANNON, P.F, DAVID, J.C. \& STALPERS, J.A. 2001. Ainsworth and Bisby's Dictionary of the fungi. $9^{\text {th }}$ ed. CABI, Wallingford.

KESHAVAPRASAD, T.S., D'SOUZA, M \& BHAT, D.J. 2003. Vermiculariopsiella Bender: present status of species diversity. In Frontiers of fungal diversity in India (Rao, G.P., Manoharachari, C., Bhat, D.J., Rajak, R.C. \& Lakhanpal, T.N. eds.). International Book Distributing Co., Lucknow. p.503-511.

MERCADO-SIERRA, A., HOLUBOVÁ-JECHOVÁ, V. \& MENA-PORTALES, J. 1997. Hifomicetos demaciáceos de Cuba, enteroblásticos. Museo Regionale di Scienze Naturali, Monografie XIII, Torino. 
NAG RAJ, T.R. 1983. Vermiculariopsiella Bender, an earlier name for Oramasia Urries. Mycotaxon 18:159-163.

NAWAWI, A., KUTHUBUTHEEN, A.J. \& SUTTON, B.C. 1990. New species and combinations in Vermiculariopsiella (Hyphomycetes). Mycotaxon 37:173-182.

PASQUALETTI, M. \& ZUCCONI, L. 1992. Vermiculariopsiella arcicula, a new dematiaceous Hyphomycete from Sardinia, Italy. Mycotaxon 43:1-7.

PIROZYNSKI, K.A. 1962. Circinotrichum and Gyrothrix. Mycological Papers 84:1-28.

PUJA, G., SHENOY, B.D., HYDE, K.D., \& BHAT, D.J. 2006. Echinosphaeria macrospora sp. nov., teleomorph of Vermiculariopsiella endophytica sp. nov. Cryptogamie Mycologie 27:11-20.

RAO, V. \& DE HOOG, G.S. 1986. New or critical Hyphomycetes from India. Studies in Mycology 28: $1-84$.
SUTTON, B.C. 1978. New and interesting hyphomycetes from Tampa, Florida. Mycologia 70:784-801.

SUTTON, B.C. 1993. Mitosporic fungi from Malawi. Mycological Papers 167:1-93.

SUTTON, B.C. \& PIROZYNSKI, K.A. 1963. Notes on British microfungi. I. Transactions of the British Mycological Society 46:505-522.

TRAPPE, J.M. \& SCHENCK, N.C. 1982. Taxonomy of the fungi forming endomycorrhizae. In Methods and principles of mycorrhizal research. (N.C. Schenck, ed.). American Phytopathological Society, St. Paul, p.1-9.

WHITMORE, T.C. 1997. Tropical forest disturbance, disappearance, and species loss. In Tropical forest remnants - ecology, management, and conservation of fragmented communities (W.F. Laurance \& R.O. Bierregard Jr., eds.). The University of Chicago Press, Chicago, p.3-12. 